\title{
Aa. Vv., La circulation des nouvelles au Moyen Âge, Actes de la Journée d'études (Université de Zurich, 24 janvier 2002)
}

Maria Colombo Timelli

\section{(2) OpenEdition}

Journals

Édition électronique

URL : https://journals.openedition.org/studifrancesi/25982

DOI : 10.4000/studifrancesi.25982

ISSN : 2421-5856

Éditeur

Rosenberg \& Sellier

Édition imprimée

Date de publication : 1 avril 2007

Pagination : 152-153

ISSN : 0039-2944

\section{Référence électronique}

Maria Colombo Timelli, «Aa. Vv., La circulation des nouvelles au Moyen Âge, Actes de la Journée d'études (Université de Zurich, 24 janvier 2002) », Studi Francesi [En ligne], 151 (LI | I) | 2007, mis en ligne le 30 novembre 2015, consulté le 23 novembre 2021. URL : http://journals.openedition.org/ studifrancesi/25982 ; DOI : https://doi.org/10.4000/studifrancesi.25982

Ce document a été généré automatiquement le 23 novembre 2021.

\section{cc) (†) $\odot$}

Studi Francesi è distribuita con Licenza Creative Commons Attribuzione - Non commerciale - Non opere derivate 4.0 Internazionale. 


\title{
Aa. $\mathrm{Vv}$., La circulation des nouvelles au Moyen Âge, Actes de la Journée d'études (Université de Zurich, 24 janvier 2002)
}

\author{
Maria Colombo Timelli
}

\section{RÉFÉRENCE}

La circulation des nouvelles au Moyen Âge, Actes de la Journée d'études (Université de Zurich, 24 janvier 2002) publiés par Luciano ROSSI, Anne B. DARMSTÄTTER, Ute LIMACHERRIEBOLD, Sara AlLOATTI BOLLER, Alessandria, Edizioni dell'Orso («Revue critique de philologie romane», Collection «Textes et études», 2), 2005, pp. 335.

1 Si l'histoire de la nouvelle médiévale reste à écrire, les études réunies dans ce volume contribuent à l'avancement de nos connaissances sur ce genre littéraire vers la fin du Moyen Âge. Après des 'Réflexions générales' confiées à Luciano Rossi et à Michel Zink, la section 'Approches théoriques' contient deux articles qui méritent d'être signalés ici.

Richard TRACHSLER, La circulation des textes au Moyen Âge: du conteur médiéval au théoricien de la littérature, pp. 29-50.

R. T. propose un parcours allant de Pietro Toldo jusqu'aux notions les plus récentes sur la circulation médiévale des textes, la pratique de la citation et l'intertextualité, en passant par G. Paris, J. Bédier, W. Foerster, R. Barthes, P. Zumthor, H. R. Jauss, K. Busby. Les exemples allégués sont tirés de la littérature arthurienne: le ms. de Cambridge, University Library, Add. 7071 (le célèbre 'Frenshe Boke' source de Chaucer), et l'épisode du roi Arthur combattant contre un monstre félin cité par Pierre Sala en 1522-23, tiré de la Suite-Vulgate du Merlin.

4 Peter FREI, La nouvelle: observations sur le récit bref en France au Moyen Âge, pp. 51-71. 
5 Après une réflexion théorique sur l'émergence de la nouvelle vers la fin $\mathrm{du} \mathrm{Xv}^{\mathrm{e}}$ siècle, menée à partir de l'analyse du discours de Michel Foucault, P. F. analyse la scène finale du Saintré pour montrer comment, au-delà d'un métalangage flou qui alterne encore 'histoire', 'nouvelle', 'conte', le texte d'Antoine de La Sale révèle une conscience aiguë de la spécificité du récit bref. Par sa force subversive, sa dimension ludique, le plaisir du texte qu'elle engendre, et surtout la crise historique et épistémologique dont elle est le reflet, la nouvelle s'avère être le genre littéraire qui illustre le mieux la continuité entre Moyen Âge et Renaissance.

6 La troisième partie, 'Le récit bref en Europe', est organisée sur la base de critères géographiques; nous nous limiterons par conséquent aux contributions ayant trait à la littérature française.

7 Yasmina FOEHR-JANSSENS, Un assemblage nouveau: les histoires sur la ruse des femmes dans la 'Disciplina clericalis' de Pierre Alphonse, pp. 225-251.

8 La richesse thématique de la Disciplina clericalis (première moitié du XII ${ }^{\mathrm{e}}$ siècle) en fait une source d'inspiration de premier plan pour les conteurs du Moyen Âge français; traduit deux fois en vers (Chastoiement d'un père à son fils et Fables de Pierre Aufons), ce recueil combine un projet didactique et une intention ludique qui s'appuient souvent sur des récits fictifs. Y. F.-J. analyse en particulier la présence et la fonction des femmes, et décèle, à côté d'une veine mysogine indéniable, une apologie de la sagesse féminine.

Jean-Claude müHLETHALER, Du 'Decameron' à 'La cité des Dames' de Christine de Pizan: modèle hagiographique et récriture au féminin, pp. 253-274.

10 Une lecture attentive de la nouvelle De la femme Bernabo le Genevois (Dec II, 9) récrite par Christine de Pizan permet d'abord de mesurer l'écart entre la source italienne et la nouvelle interprétation morale établie par la poétesse; d'autre part, ce récit renforce indubitablement la parenté entre les histoires réunies dans les deux premiers livres (tirées du De claris mulieribus) et les récits hagiographiques du troisième livre de la Cité, inspirés essentiellement du Miroir historial de Vincent de Beauvais traduit par Jean de Vignay. Par cette lecture, J.-Cl. M. prouve la profondeur du travail de récriture fait par Christine, qui, tout en suivant la nouvelle du Decameron, s'inspire du discours hagiographique et tisse en même temps des liens étrangers à sa source première.

11 Nelly LABÈRE, 'La fresche memoire': génération et régénération dans les 'Cent Nouvelles nouvelles', pp. 275-283.

12 La nouveauté semble s'afficher comme un des traits caractérisant le genre de la nouvelle: à partir de cette constatation, N. L. s'interroge sur le prétendu rapport de filiation que l'auteur des $\mathrm{CNn}$ établit avec le Décaméron. Elle signale d'abord ce qui sépare le recueil bourguignon de l'œuvre de Boccace: la disparition du récit-cadre, la réduction des devisants à de simples inscriptions nominales, et surtout la revendication, de la part de l'auteur français, de la 'fraîcheur' de ses contes. Tout cela permet de conclure que la véritable 'nouveauté' des $\mathrm{CNn}$ consiste justement dans la temporalité: les récits proposés se situent tous dans la mémoire, directe ou indirecte, du conteur. Remarquons toutefois qu'il est risqué d'établir une comparaison entre le Décaméron et les $\mathrm{CNn}$ sans tenir compte de la traduction fournie par Laurent de Premierfait en 1414, dont le titre est justement Livre des Cent Nouvelles.

13 Raphael zeHnDER, De l'anecdote au scénario complet: de la 'Facétie' 157 du Pogge à la $8^{\mathrm{e}}$ des 'Cent Nouvelles nouvelles', pp. 285-309. 
14 La huitième des $\mathrm{CNn}$ se démarque de sa source latine par la dilatation du récit, fondée sur l'amplification stylistique et syntaxique, et sur le ralentissement du rythme narratif. Cependant, les mécanismes du rire (comique de situation et comique verbal) restent sensiblement les mêmes dans la 'facetia' latine et dans la 'nouvelle' bourguignonne.

15 Anne B. DARMSTÄTTER, Les 'Cent Nouvelles nouvelles': la nouveauté créatrice du passé?, pp. 311-335.

16 Il s'agit d'une lecture quelque peu hasardeuse des nouvelles IV, XCVI, LXXVII (interprétées sur la base de la métaphysique aristotélicienne), et XX (qui cacherait une réflexion sur le genre romanesque et sur la nouvelle). 